\title{
A modified Delphi study to gain consensus for a taxonomy to report and classify physical activity referral schemes (PARS)
}

\author{
Coral L. Hanson ${ }^{1 *}$ (D) Emily J. Oliver ${ }^{2}$, Caroline J. Dodd-Reynolds ${ }^{2}$, Alice Pearsons ${ }^{1}$ and Paul Kelly ${ }^{3}$
}

\begin{abstract}
Background: Physical Activity Referral Schemes (PARS), including exercise referral schemes, are a popular approach to health improvement, but understanding of effectiveness is limited by considerable heterogeneity in reporting and evaluation. We aimed to gain consensus for a PARS taxonomy as a comprehensive method for reporting and recording of such schemes.
\end{abstract}

Methods: We invited 62 experts from PARS policy, research and practice to complete a modified Delphi study. In round one, participants rated the need for a PARS taxonomy, the suitability of three proposed classification levels and commented on proposed elements. In round two, participants rated proposed taxonomy elements on an 11-point Likert scale. Elements scoring a median of $\geq 7$, indicating high agreement, were included in the final taxonomy.

Results: Of those invited, 47 (75.8\%) participated in round one, with high retention in round two $(n=43 ; 91.5 \%) .42$ were UK-based, meaning the resultant taxonomy has been scrutinised for fit to the UK context only. The study gained consensus for a three-level taxonomy: Level 1: PARS classification (primary classification, provider, setting, conditions accepted [have or at risk of], activity type and funding). Level 2: scheme characteristics (staff structure, staff qualifications, behaviour change theories, behaviour change techniques, referral source, referrers, referral process, scheme duration, session frequency, session length, session times, session type, exit routes, action in case of nonattendance, baseline assessment, exit assessment, feedback to referrer and exclusion criteria) and Level 3: participant measures (demographics, monitoring and evaluation, and measures of change).

Conclusion: Using a modified Delphi method, this study developed UK-based consensus on a PARS classification taxonomy. We encourage PARS practitioners and public health colleagues, especially those working with similar service models internationally, to test, refine and use this taxonomy to inform policy and practice.

Keywords: Physical activity, Public health, Exercise referral, Evaluation, Rehabilitation medicine

\footnotetext{
* Correspondence: c.hanson@napier.ac.uk

'School of Health and Social Care, Edinburgh Napier University, Sighthill Campus, Edinburgh EH11 4DN, UK

Full list of author information is available at the end of the article
}

(c) The Author(s). 2020 Open Access This article is licensed under a Creative Commons Attribution 4.0 International License, which permits use, sharing, adaptation, distribution and reproduction in any medium or format, as long as you give appropriate credit to the original author(s) and the source, provide a link to the Creative Commons licence, and indicate if changes were made. The images or other third party material in this article are included in the article's Creative Commons licence, unless indicated otherwise in a credit line to the material. If material is not included in the article's Creative Commons licence and your intended use is not permitted by statutory regulation or exceeds the permitted use, you will need to obtain permission directly from the copyright holder. To view a copy of this licence, visit http://creativecommons.org/licenses/by/4.0/ The Creative Commons Public Domain Dedication waiver (http://creativecommons.org/publicdomain/zero/1.0/) applies to the data made available in this article, unless otherwise stated in a credit line to the data. 


\section{Introduction}

Physical inactivity is responsible for $6.4 \%$ of global mortality, contributing an estimated $\$ 53.8$ billion to healthcare costs worldwide in 2013 [1]. Adults who are more active have better physical and mental health, and higher quality of life [2]. Despite this, globally, more than one in four people were insufficiently active in 2018, with women less active than men [2].

Exercise referral schemes, established in the 1990's, are an internationally recognised way to 'prescribe' activity to enable people to achieve recommended levels of PA $[3,4]$. In the UK, traditionally, a patient with a health condition, or other factors putting them at risk of ill health, would be referred by a healthcare professional if they were sedentary or inactive. This was followed by referral to a PA specialist/service, a personal needs assessment and an opportunity to participate in PA over 10 weeks or longer [5-7]. Other nations have exercise referral systems, however variation exists in terms of policies, referral mechanisms and practices. In some countries healthcare professionals 'prescribe' exercise rather than fitness professionals, although PA usually takes place in the community as it does in the UK. For example, Sweden's 'Physical Activity on Prescription' model, currently being trialled in other European countries, [8] consists of healthcare professionals having a patient-centred discussion and producing an individually tailored written PA prescription, which is followed-up by the same prescriber [9]. Similarly, the American College of Sports Medicine's 'Exercise is Medicine' model stresses PA brief advice and basic exercise prescription by healthcare professionals after an assessment of readiness to change PA behaviour. Mechanisms for establishing referrals to fitness professionals do exist, [10] making some aspects of Exercise is Medicine comparable to UK schemes. The Australian model is the most similar to the UK model, as it allows referrals specifically to exercise physiologists where a chronic medical condition has been diagnosed [11].

In the UK, physical activity services have broadened in recent years and (as we have previously reported) the term 'exercise referral' now fails to accurately represent the range of schemes available [12]. This is the case both in terms of evidence-informed models and contemporary practices, such as social prescribing, where patients can be referred via link workers into local community groups (across health, arts, culture and sport) and selfreferral, where an individual can request direct entry into a scheme, rather than referral by a healthcare practitioner. We have suggested that the broader and more inclusive definition of 'physical activity referral schemes' (PARS), which includes all schemes that offer supported PA options/choices for individuals with a health condition, recognises such recent innovation in supporting PA uptake [12].
Current understanding of PARS effectiveness is limited by considerable heterogeneity in available data reported both by individual schemes $[13,14]$ and at systematic review level $[15,16]$. Quality of reporting is variable: e.g. around scheme delivery components and processes or evaluation-based appraisals [17]. The result is ambiguity in understanding of effectiveness and a lack of policy guidance for best practice or practices (e.g. if best practice varies by context or client type), and a lack of understanding about 'what good looks like' [17]. A shift in recognition and understanding of PARS is needed to advance policy, evidence and practice. There is a clear need for full documentation of practical details within scheme provision and delivery in order to understand the existing heterogeneity across schemes nationally and internationally. This will better-inform future policy, commissioning, and delivery.

We therefore propose the generation of a comprehensive framework for reporting and recording scheme details. To achieve this, a rigorous process must be undertaken to extract critical knowledge and insight from PARS experts across policy, research and practice. A Delphi study is a widely adopted and well-accepted systematic method to achieve consensus of expert opinion $[18,19]$. We report the process and findings from a modified Delphi study, undertaken to inform the development of a PARS classification taxonomy, grounded in both theory and practice-based experience.

\section{Method}

A modified Delphi study that gained UK-based consensus for a PARS taxonomy (Fig. 1) following the guidance on Conducting and REporting of DElphi Studies (CREDES) [20].

\section{Exploration and pilot stage}

We established a steering group of four UK-based researchers with expertise in PARS, behaviour change theory and research/evaluation methods $(\mathrm{CH}, \mathrm{PK}, \mathrm{CDR}$, EO) to develop an initial taxonomy framework. A preliminary review of relevant UK guidelines, literature and steering group perspectives informed the development of a prototype three-level PARS taxonomy. To allow for the gathering of wider viewpoints, two researchers $(\mathrm{CH}$, PK) presented the prototype taxonomy to PARS and public health experts $(n=57)$ at a Scottish NHS Information Exchange in September 2019. After the presentation, we encouraged open-ended discussion and made field notes about comments. We asked attendees to provide written comments on a printed version of the taxonomy, and promoted both supportive and conflicting feedback. The author team considered all observations and updated the framework accordingly. The proposed taxonomy consisted of a high-level classification figure and a checklist of PARS elements [12]. 


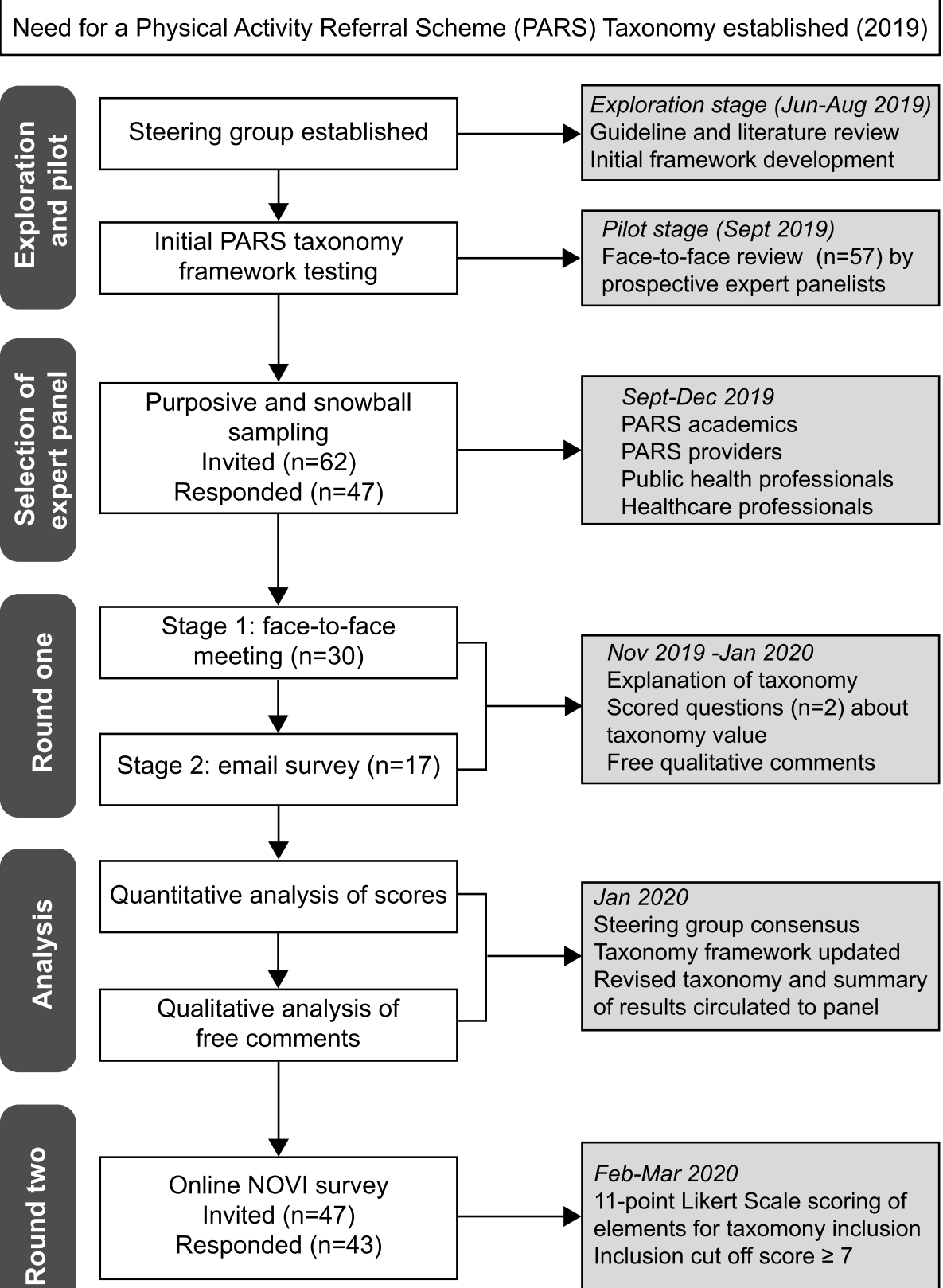

Fig. 1 Flow diagram of modified Delphi study process

\section{Recruitment of expert panel}

We defined experts as 'individuals involved in the conception, design, conduct, teaching or analysis of PARS.' We used purposive and snowball sampling to invite more than the suggested minimum 20 contributors [21] to form an expert panel. Professional backgrounds included (a) academics/researchers and published authors in the PARS field, (b) providers of PARS and (c) public health and healthcare professionals involved in PARS.
For invited participants, there were no exclusion criteria. We invited experts to participate via email and provided participant information packs. We received expressions of interest from people in five different countries (UK, Ethiopia, Canada, Ireland and Australia), but only one participant from outside the UK (Australia) completed the study, making the results valid for UK-based PARS. To reduce the risk of bias from the steering group, an independent researcher (AP) co-ordinated the study. 


\section{Round one}

We conducted an initial face-to-face meeting in November 2019 as part of a free one-day specialist workshop, with invited academic presentations from UK PARS researchers. We advertised the workshop via UK national public health networks, and international university networks and social media. We followed this with a second stage of remote email questionnaires for those unable to attend the meeting or who contacted us via snowball sampling. All participants gave written signed consent. At the face-to-face meeting, we formally presented the taxonomy before asking panellists to complete the first survey round. For email panellists we provided an explanation document. During the meeting, we used Slido (https://www.sli.do/) to collect anonymous feedback and asked experts to score two introductory questions on an 11-point Likert scale (0-Do not agree at all, 10-Agree very strongly):

1. Do you believe there is value in developing a PARS taxonomy?

2. Do you agree that we need a three-level approach (primary classification, scheme characteristics and participant measures) to the proposed taxonomy?

We then asked panellists to move systematically through the taxonomy and make free comments about each element. We encouraged both supportive and critical feedback, and requested detailed justification for any suggestions of missed or superfluous items to help revise the next iteration of the taxonomy. The steering group analysed quantitative scoring, and collated and discussed qualitative comments, before adapting the proposed taxonomy prior to the second round.

\section{Round two}

In round two, we disseminated an updated taxonomy, an explanation of changes and a summary of anonymised first round comments to the expert panel. We asked panellists to complete an online NOVI survey (https://novisurvey.net/) and score each taxonomy element on an 11-point Likert scale (0-Unimportant, do not include in taxonomy, 10-Very important, must be included in taxonomy). Using a measure of central tendency as a definition of consensus, [22] we informed participants that the cut off for element inclusion in the taxonomy was a score of $\geq 7$. We asked panellists to comment on, but not score, sub-elements (e.g. conditions accepted by schemes). This was because the taxonomy design allowed for local adaptations (e.g. the addition of a further medical condition, while maintaining conditions identified earlier in the process as being most common), thus did not cover all potential variations of scheme provision.

\section{Data analysis}

Quantitative data were analysed using SPSSv26 (IBM, NY, USA). We examined the data distribution of each score by calculating z-scores for skewness and kurtosis, and via Shapiro-Wilks tests. We reported the median and interquartile range (IQR) of overall scores for each taxonomy element and by professional group. Items scoring $\geq 7$ overall were included in the final taxonomy.

Our approach to responding to comments raised through the consultation phases adopted three basic principles. (1) We reviewed all comments taking into account the number of panellists making similar comments. We acted on comments made by one individual in exception, as these were considered outlying discrepant viewpoints from the consensus. (2) Where we considered that suggestions for additions to any taxonomy element could be adequately recorded in an 'other' category, we did not make an amendment. (3) All authors discussed responses to comments and made decisions about subsequent actions as a team. We agreed small changes to sub-elements provided we could sufficiently justify them based on qualitative comments and author group consensus.

\section{Results}

In total, we invited 62 experts to participate (inviting 36 to a face-to-face meeting and 26 via snowball sampling and social media advertising). We received 47 responses (75.8\% response rate). Thirty $(63.8 \%)$ attended the faceto-face meeting and $17(36.2 \%)$ responded via an email questionnaire. We only invited respondents from round one to participate in round two. Forty-three $(91.5 \%$ of round one respondents) completed round two. Of the 43 study completers, 16 (37.2\%) were academics/researchers, 12 (27.9\%) were PAR providers/commissioners, six (14.0\%) were both a researcher and a PARS provider, and nine (20.9\%) were public health/healthcare professionals. Most panellists were UK-based, with one from Australia, validating the taxonomy in a UK context.

\section{Round one results}

Participants considered there was value in developing a PARS taxonomy (median score 10.0, [IQR 9.0-10.0]) and that a three-level approach (primary classification, scheme characteristics and participant measures) was appropriate (median score 8.0, [IQR 7.0-9.5]).

Based on qualitative comments from panellists, we made minor amendments to most elements of the initial taxonomy. We made five major changes. First, in the figure, we redefined level 1a (primary classification) to better reflect types of schemes offered, removing the previous terminology of 'traditional' versus 'non-traditional' PARS.

We received some comments that PARS must include explicit behaviour change support but not all panellists 
agreed, stating that schemes without explicit behaviour change support should be included in the taxonomy. Second, we moved funding (level 1e) up into the PARS classification level of the taxonomy from level 2, reflecting its importance in determining scheme type.

Third, in the checklist, we changed level 1a to include two sets of questions that would allow for high-level scheme classification (Table 1).

Fourth, we amended level 2c (behaviour change theories) to a more general question about whether a PARS was based on behaviour change theory, and added a further section (level 2d, behaviour change techniques) as these were considered more easily identifiable by providers completing the taxonomy. Finally, we added in three new subsections to scheme characteristics (level 2j, session length, level $2 \mathrm{k}$, session times and level $2 \mathrm{~s}$, exclusion criteria). We made minor changes to the details within taxonomy subsections, but recognised that these could not reflect every variation of every scheme, so where appropriate ensured each subsection had an 'other' element.

\section{Round two results}

Scoring of elements for inclusion in the PARS taxonomy

The scores for each element did not follow a normal distribution. With the exception of 'equipment loan', all taxonomy elements scored a median of $\geq 7$ and were included in the final consensus (Table 2). The median score for PARS providers was below $\geq 7$ for length and time of sessions, but overall these items gained consensus.

\section{Level 1: primary classification}

Sixteen panellists commented on primary classification. Overall, they consistently supported the main elements in this taxonomy level and comments were mainly confirmatory. However, panellists suggested clarification of key terms, additional sub-elements, or minor edits to wording. We agreed five minor amendments to subelements of level $1 \mathrm{~b}$ (provider and setting) and 1d (activity type) in both the figure and the checklist. These included adding an option for a clinical setting, since panellists felt that the taxonomy was valuable for clinical exercise programmes. We changed wording to request additional detail for all level 1 elements in the third column of the checklist (e.g. specifying the exact venue and location of PARS setting). Finally, we added detail to level 1a questions in the checklist; 'explicit, planned behaviour change techniques included e.g. goal setting, formalised activity tracking/activity monitoring' to clarify the meaning of individual behaviour change consultations and examples of signposting to generic activities 'e.g. walking football, Pilates and Zumba'.

\section{Level 2: scheme characteristics}

Eighteen panellists commented on scheme characteristics. As with level 1, many comments confirmed agreement with the elements in level 2. Seven minor edits were made to item and checklist wording, including the addition of examples to aid clarity (e.g. of PARS specific qualifications). Additionally, we discussed two other areas of feedback.

First, comments questioned the necessity of retaining both level 2e (referral source) and level 2f (referrers) categories. We noted potential difficulties in categorising primary, secondary or tertiary care referrals based on referrer role title, as some job titles span multiple domains. We considered that the ability to examine schemes based on

Table 1 Level 1a: primary classification questions

\section{Physical Activity Referral Scheme (PARS) Reporting Checklist}

\section{Level 1 PARS classification}

Level 1a: Primary classification

The purpose of this taxonomy is to provide a classification system for PARS, including clinically based exercise schemes, exercise referral schemes and social prescribing for physical activity (PA). It is for use in evidence reviews of delivery and effectiveness. It is also an audit and monitoring tool for funders and providers to capture service delivery. The taxonomy is intended for programmes that fulfil all of the following three criteria

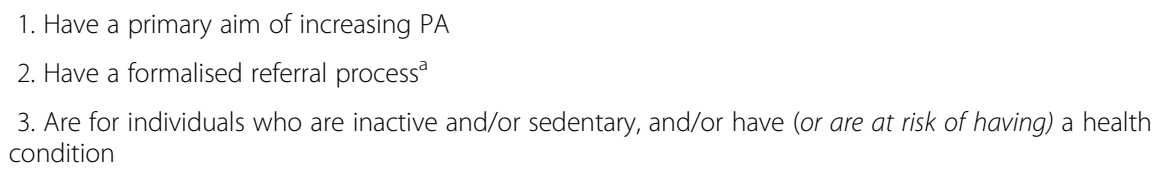

If you have not ticked all of these boxes, then the PARS taxonomy is not suitable for your programme.

${ }^{a}$ An agreed and documented process for the transfer of referral information between health/social care referrers and PARS providers, which leads to individuals being able to access PARS 
Table 2 Round two scoring of elements for inclusion in the PARS taxonomy

\begin{tabular}{|c|c|c|c|c|c|c|c|c|c|c|}
\hline \multirow[t]{2}{*}{ Taxonomy element } & \multicolumn{2}{|c|}{$\begin{array}{l}\text { Academic/ } \\
\text { Researcher } \\
(n=16)\end{array}$} & \multicolumn{2}{|c|}{$\begin{array}{l}\text { PARS provider/ } \\
\text { commissioner } \\
(n=12)\end{array}$} & \multicolumn{2}{|c|}{$\begin{array}{l}\text { Both researcher } \\
\text { and PARS } \\
\text { provider }(n=6)\end{array}$} & \multicolumn{2}{|c|}{$\begin{array}{l}\text { Public health } \\
\text { or healthcare } \\
\text { professional } \\
(n=9)\end{array}$} & \multicolumn{2}{|c|}{$\begin{array}{l}\text { All panellists } \\
(n=43)\end{array}$} \\
\hline & Median & IQR & Median & IQR & Median & IQR & Median & IQR & Median & IQR \\
\hline \multicolumn{11}{|l|}{ LEVEL 1 PARS classification } \\
\hline 1a) Primary classification & 9.5 & $8.3-10.0$ & 9.5 & $8.0-10.0$ & 10.0 & $9.8-10.0$ & 10.0 & $6.0-10.0$ & 10.0 & $8.0-10.0$ \\
\hline 1b) Provider & 10.0 & $9.0-10.0$ & 8.0 & $4.8-9.8$ & 10.0 & $8.8-10.0$ & 9.0 & $7.5-9.5$ & 9.0 & $8.0-10.0$ \\
\hline 1b) Setting & 10.0 & $9.0-10.0$ & 7.0 & $7.0-8.0$ & 10.0 & $8.8-10.0$ & 9.0 & $7.5-9.5$ & 9.0 & $7.0-10.0$ \\
\hline $\begin{array}{l}\text { 1c) Conditions accepted } \\
\text { (have or at risk of) }\end{array}$ & 10.0 & $9.3-10.0$ & 10.0 & $8.3-10.0$ & 10.0 & $8.8-10.0$ & 10.0 & $8.0-10.0$ & 10.0 & $9.0-10.0$ \\
\hline 1d) Activity type & 10.0 & $9.3-10.0$ & 9.5 & $7.0-10.0$ & 9.0 & $6.5-10.0$ & 9.0 & $8.0-9.5$ & 10.0 & $8.0-10.0$ \\
\hline 1e) Funding & 10.0 & $8.0-10.0$ & 7.0 & $5.0-8.8$ & 8.0 & $6.5-9.3$ & 9.0 & $5.5-10.0$ & 8.0 & $7.0-10.0$ \\
\hline \multicolumn{11}{|l|}{ LEVEL 2 Scheme characteristics } \\
\hline 2a) Staff structure & 9.0 & $7.3-10.0$ & 8.5 & $3.5-9.8$ & 9.5 & $5.8-10.0$ & 8.0 & $4.5-8.5$ & 9.0 & $6.0-10.0$ \\
\hline 2b) Staff qualifications & 10.0 & $9.0-10.0$ & 10.0 & $9.0-10.0$ & 10.0 & $9.0-10.0$ & 9.0 & $7.0-10.0$ & 10.0 & $9.0-10.0$ \\
\hline 2c) Behaviour change theories & 9.0 & $6.3-10.0$ & 7.0 & $6.3-9.5$ & 10.0 & $8.8-10.0$ & 8.0 & $5.5-10.0$ & 8.0 & $7.0-10.0$ \\
\hline 2d) Behavioural change techniques & 9.0 & $8.0-10.0$ & 8.0 & $7.0-10.0$ & 10.0 & $8.8-10.0$ & 8.0 & $5.0-10.0$ & 9.0 & $7.0-10.0$ \\
\hline 2e) Referral source & 9.0 & $7.0-10.0$ & 8.0 & $7.0-10.0$ & 9.5 & $7.8-10.0$ & 9.0 & $7.5-10.0$ & 9.0 & $7.0-10.0$ \\
\hline 2f) Referrers & 10.0 & $9.3-10.0$ & 8.0 & $7.0-9.8$ & 9.5 & $7.5-10.0$ & 9.0 & $6.5-10.0$ & 9.0 & $8.0-10.0$ \\
\hline 2g) Referral process & 9.5 & $6.5-10.0$ & 8.0 & $7.0-10.0$ & 10.0 & $8.5-10.0$ & 8.0 & $4.5-10.0$ & 9.0 & $7.0-10.0$ \\
\hline 2h) Scheme duration & 10.0 & $10.0-10.0$ & 9.0 & $7.0-10.0$ & 10.0 & $9.0-10.0$ & 10.0 & $8.0-10.0$ & 10.0 & $9.0-10.0$ \\
\hline 2i) Session frequency & 10.0 & $10.0-10.0$ & 9.0 & $5.5-10.0$ & 9.5 & $7.3-10.0$ & 9.0 & $8.0-10.0$ & 10.0 & $8.0-10.0$ \\
\hline 2j) Session length & 10.0 & $7.5-10.0$ & 6.5 & $5.0-7.8$ & 9.5 & $5.3-10.0$ & 9.0 & $7.5-9.5$ & 9.0 & $6.0-10.0$ \\
\hline 2k) Session time & 8.0 & $5.0-10.0$ & 6.0 & $2.0-7.0$ & 7.0 & $5.3-10.0$ & 8.0 & $6.5-9.0$ & 7.0 & $5.0-9.0$ \\
\hline 21) Session type & 10.0 & $9.3-10.0$ & 8.0 & $7.0-10.0$ & 10.0 & $8.5-10.0$ & 9.0 & $7.5-10.0$ & 10.0 & $8.0-10.0$ \\
\hline 2m) Equipment loan ${ }^{a}$ & 5.0 & $3.3-7.8$ & 0.5 & $0.0-5.0$ & 6.0 & $4.5-7.0$ & 5.0 & $4.0-7.0$ & $5.0^{\mathrm{a}}$ & $3.0-7.0$ \\
\hline 2n) Exit routes & 9.5 & $9.0-10.0$ & 9.0 & $7.3-10.0$ & 9.5 & $7.0-10.0$ & 8.0 & $7.5-10.0$ & 9.0 & $8.0-10.0$ \\
\hline 20) Action in case of non-attendance & 9.5 & $9.0-10.0$ & 8.5 & $4.3-10.0$ & 10.0 & $7.5-10.0$ & 8.0 & $7.5-10.0$ & 9.0 & $8.0-10.0$ \\
\hline 2p) Baseline assessment & 10.0 & $10.0-10.0$ & 10.0 & $9.3-10.0$ & 10.0 & $9.0-10.0$ & 10.0 & $7.5-10.0$ & 10.0 & $10.0-10.0$ \\
\hline 2q) Exit assessment & 10.0 & $10.0-10.0$ & 10.0 & $10.0-10.0$ & 10.0 & $9.0-10.0$ & 10.0 & $7.5-10.0$ & 10.0 & $10.0-10.0$ \\
\hline 2r) Feedback provided to referrer & 10.0 & $9.0-10.0$ & 7.0 & $5.0-9.8$ & 9.0 & $7.0-10.0$ & 8.0 & $7.5-9.5$ & 9.0 & $7.0-10.0$ \\
\hline 2s) Exclusion criteria & 10.0 & $9.3-10.0$ & 10.0 & $7.3-10.0$ & 9.5 & $7.8-10.0$ & 10.0 & $8.5-10.0$ & 10.0 & $9.0-10.0$ \\
\hline \multicolumn{11}{|l|}{ LEVEL 3 Participant characteristics } \\
\hline 3a) Demographics & 10.0 & $9.3-10.0$ & 10.0 & $8.5-10.0$ & 9.5 & $8.3-10.0$ & 10.0 & $7.0-10.0$ & 10.0 & $9.0-10.0$ \\
\hline 3b) Number of referrals & 10.0 & $9.3-10.0$ & 10.0 & $7.3-10.0$ & 9.5 & $7.8-10.0$ & 10.0 & $7.0-10.0$ & 10.0 & $8.0-10.0$ \\
\hline 3c) Uptake, attendance and adherence & 10.0 & $10.0-10.0$ & 10.0 & $8.5-10.0$ & 9.5 & $8.5-10.0$ & 10.0 & $8.0-10.0$ & 10.0 & $9.0-10.0$ \\
\hline 3d) Measures of Change & 10.0 & $10.0-10.0$ & 10.0 & $8.5-10.0$ & 9.5 & $8.5-10.0$ & 10.0 & $8.5-10.0$ & 10.0 & $9.0-10.0$ \\
\hline
\end{tabular}

${ }^{\mathrm{a}}$ Excluded from the final taxonomy

where (in the healthcare continuum) PARS received referrals from, was important and therefore retained both levels in the final taxonomy. Second, some panellists commented that exclusion criteria listed were too specific, having different terminology between schemes, and focussing overly on medical criteria for exclusion. In response, we decided to remove the list and ask users to detail exact exclusion criteria.

\section{Level 3: participant characteristics}

Thirteen panellists commented on participant characteristics, reporting that recording demographics was important to create local and national evidence of impact, especially in gauging whether PARS successfully targeted those with the largest health and PA inequalities. Panellists considered some demographics more important (age, gender and socioeconomic status). We did not remove any demographic 
sub-category, however noted a requirement to stress that the taxonomy is not prescriptive, but is a tool to classify schemes: what is being delivered, by whom and how.

One panellist questioned whether elements 3b-3d (number of referrals, uptake, attendance and adherence, and measures of change) were about evaluation rather than the stated taxonomy aim of describing PARS. This panellist suggested that these elements should have a sub-heading of 'monitoring and evaluation' above level 3b for clarity. We agreed this was an important suggestion and added the new subheading to create an area where users could record what is, or has been evaluated, and how. However, the checklist does not mandate that users must conduct an evaluation in order to complete the taxonomy.

Some panellists identified repetition between the level 2n/2o categories 'baseline assessment' and 'exit assessment' and level 3d 'measures of change'. We removed details of the measures from level $2 \mathrm{n} / 2 \mathrm{o}$. We considered the minor changes made to sub-elements were justifiable posteriori considerations, [18] and that the Delphi study had reached consensus, as all agreed elements were retained in the taxonomy.

The study resulted in the creation of a Level 1: PARS classification diagram (Fig. 2), a Level 2: Scheme characteristics diagram (Fig. 3), a level 3: Participant measures diagram (Fig. 4) and a taxonomy checklist (see Additional file 1).

\section{Discussion}

This research used a modified Delphi method that developed a UK validated PARS classification taxonomy endorsed by academics, practitioners, and scheme providers. In doing so, we have developed an expert-informed tool, perceived as both functionally viable by intended users and informative for stakeholders. Hence, we encourage PARS providers and researchers to report consistently and publicly scheme characteristics using the taxonomy. Doing so will facilitate the generation of robust and comprehensive data to better understand the nature of PARS provision. Given the proliferation in, and differentiation of, PARS practices, we are at a critical point in terms of ensuring that understanding of what works, for whom, can be advanced. Importantly, standardising reporting will enable the collation of data from similar schemes and inform betweenscheme comparisons recommended by previous authors $[10,12]$. This will facilitate future monitoring and evaluation, essential for appropriately, and effectively supporting public health policy and practice [23].

\section{The inclusion of behaviour change theory and techniques in PARS}

The necessity, or otherwise, of including behaviour change theory and techniques in PARS was the most debated element of this study. Some panellists, generally providers, considered that the 'traditional' necessity in the UK $[6,7]$ of including formal behaviour change led to limited recognition of many contemporary PARS. The evidence for the successful implementation of formal behaviour change into PARS is equivocal, [24, 25] but there has been little examination of whether informal behaviour change techniques are integral to such schemes. Given this, we ensured that the taxonomy captured the presence or absence of individual behaviour change consultations at level 1 , and that level 2 provided an opportunity for detailed capture of any underlying theoretical principles and behaviour change techniques included in PARS. Given that behaviour change taxonomies developed elsewhere have, for example close to 100 elements, [26] with up to 21 techniques based on one specific theory, [27] we decided not to include examples. This prevents any risk of biasing or narrowing responses.

\section{Strengths and limitations}

Delphi studies provide a means to arrive at justifiable, valid and credible solutions based on expert judgement [28]. However, we recognise that the decision-making process inevitably involves subjectivity and judgemental inputs, in terms of panel selection, item selection, and resolution of contention [29]. While we ensured anonymity between participants (using anonymous software and online-data capture), not all researchers were always blind to comments when returned via email. Lastly, panel consensus methods can involve a 'watering down' of opinions and ideas [30]. It is possible that the taxonomy may need future development to capture particularly innovative or emerging characteristics linked with scheme effectiveness.

We are aware that the Delphi panel were UK-centric, and invite further refinement of the taxonomy from international colleagues, including non-PARS focused experts. Given that models in some other countries focus on healthcare professionals providing an exercise prescription, $[9,10]$ further consultation with international experts may highlight a need for adaptations to the taxonomy to make it more relevant in these countries.

The challenges of capturing evaluation data and evaluation in health programmes are widely discussed [31]. The PARS taxonomy, formed by expert consensus across a range of UK stakeholders, represents a first step in producing a robust system for capturing detailed programme delivery, structure and operational detail that is required for between-programme evaluation to identify best practice or practices in the UK.

\section{Implications for policy and practice}

We suggest that the PARS taxonomy is used to classify, record and report PARS delivery. It is our intention that 


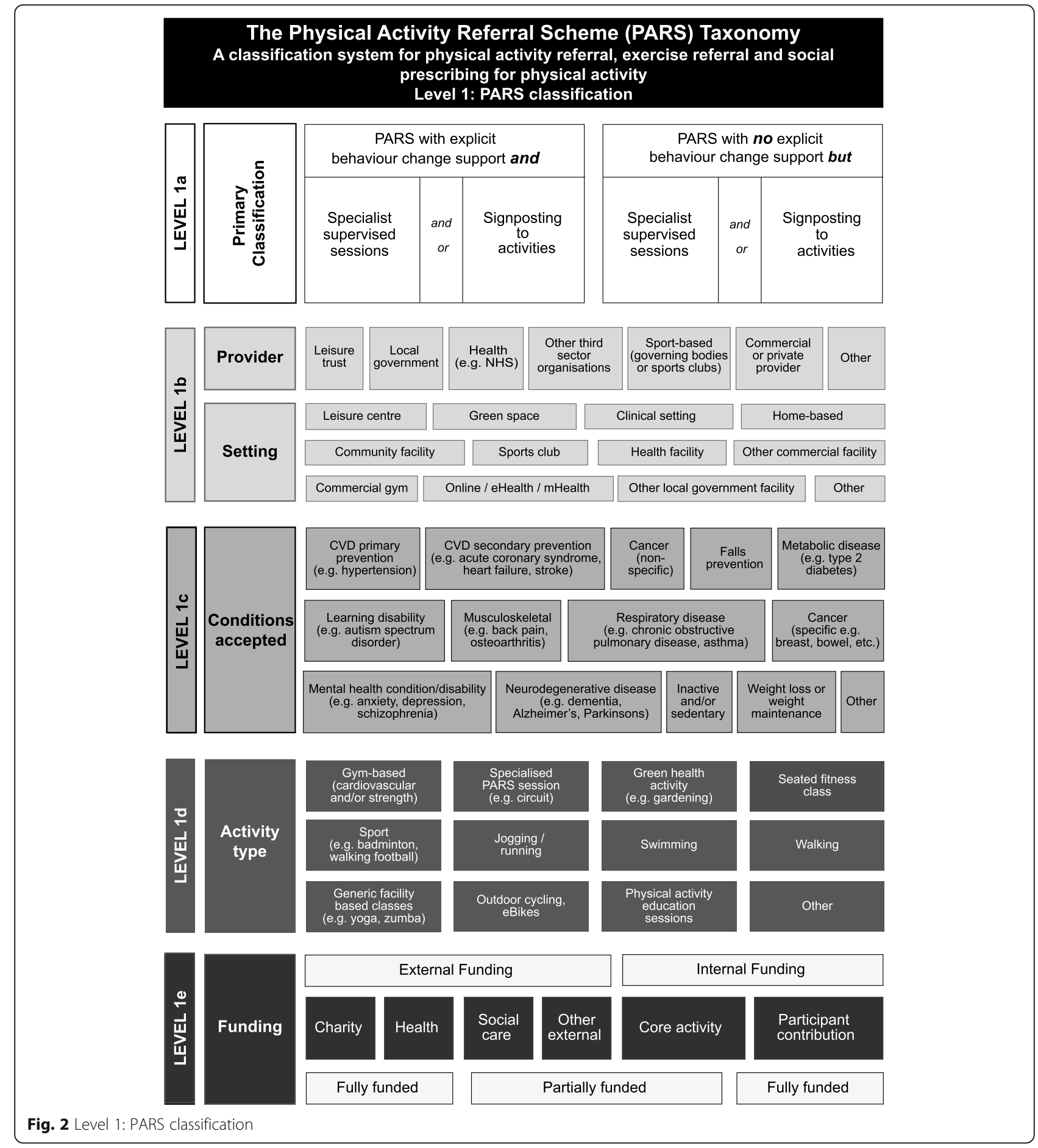

this would be done at a "scheme level" so that a provider delivering different PARS would complete separate reporting checklists for each scheme. If providers are delivering a generic scheme for different medical conditions, we suggest that medical condition is recorded at individual participant level to allow for assessment of success for different conditions.
We also suggest a number of recommendations for future development. First, that data generated from use of the taxonomy should be audited regularly to identify required adaptations based on changing provision landscapes. Revisions of the taxonomy should invite stakeholder engagement in the same way as the present version, and be publicly available for use. Second, stakeholders should 


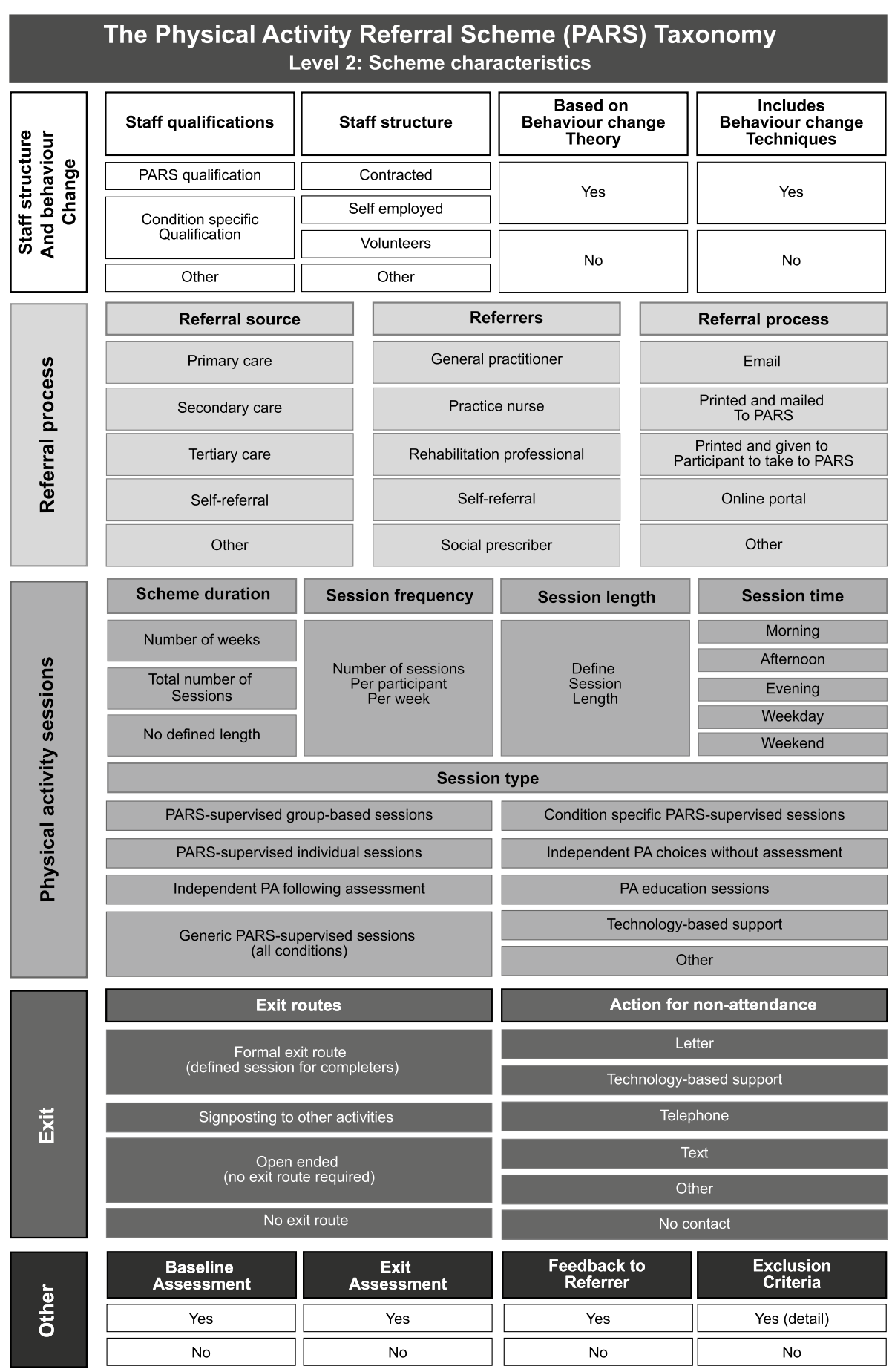

Fig. 3 Level 2: Scheme characteristics

collaborate to develop systems and processes for data sharing and subsequent evaluation, as well as disseminating findings back to practitioners. This should include national and regional organisations who are using the taxonomy streamlining collection, processing and analysis of data in effective monitoring and evaluation systems. Without linking the taxonomy to accompanying outcome evaluation data, understanding of effective and ineffective practices is constrained. Third, we encourage the user to have flexibility to go to the level of depth appropriate. With minimal time and capacity they should rapidly be able to complete level one to provide a high-level monitoring system with information about scheme type (a minimum dataset so to speak). When a more in depth 


\section{The Physical Activity Referral Scheme (PARS) Taxonomy Level 3: Participant measures}
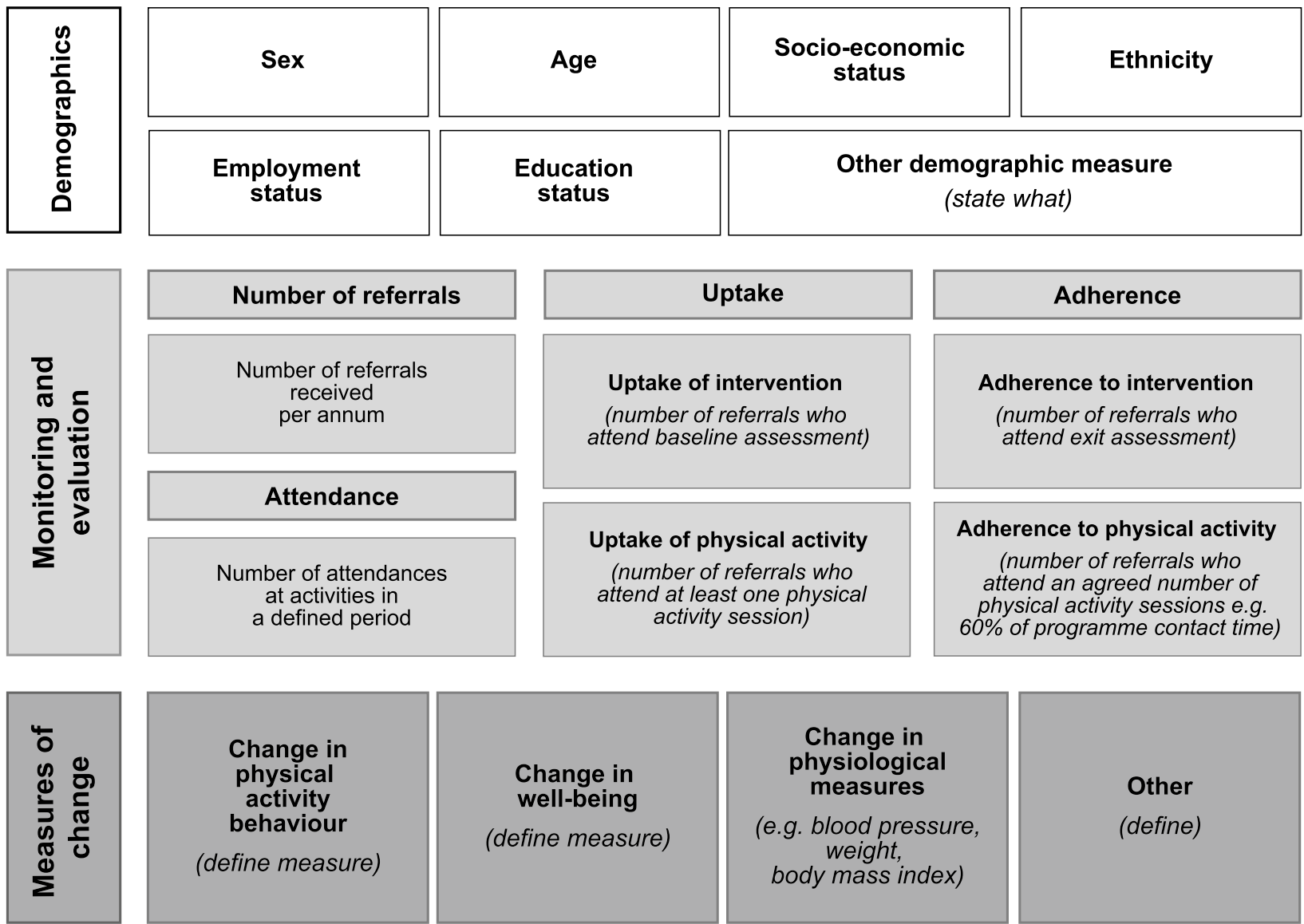

Uptake
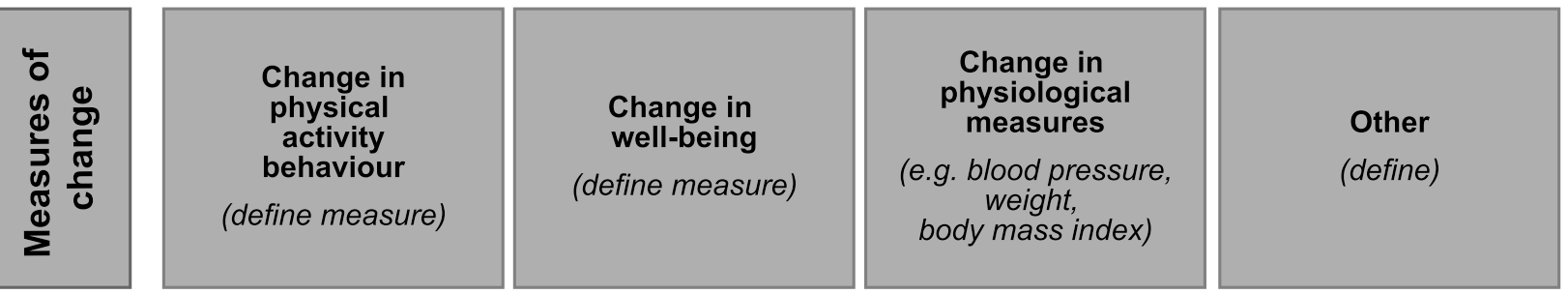

Fig. 4 Level 3: Participant measures

evaluation is warranted the information at levels 2 and 3 can be collected and analysed as well, but still in harmony with data from PARS that only collect/report at level 1. Lastly, while we accept that local variations may be useful to capture subtle differences in provision, we recommend that the present taxonomy is seen as a minimum reporting standard. While elements may be added to the taxonomy, we advise against removal of elements from the level at which it is being used. Instead, users should note 'not applicable' or 'not available' (as with monitoring and evaluation above). This is important to maintain the intended purpose of capturing comparable data across schemes.

\section{Conclusion}

This research used a modified Delphi method to develop a UK-based consensus on a PARS classification taxonomy. We suggest that the reporting taxonomy complements and is used alongside UK policy guidance in designing, monitoring and evaluating PARS. In addition, we encourage international consideration and feedback about suitability for use outside the UK and would welcome further collaboration to develop an international consensus for a PARS taxonomy.

\section{Supplementary Information}

The online version contains supplementary material available at https://doi. org/10.1186/s12966-020-01050-2.

Additional file 1.

Acknowledgements

Not applicable.

Authors' contributions

$\mathrm{CH}$ and PK conceptualised the idea of a PARS taxonomy, which was developed by $\mathrm{CH}, \mathrm{PK}, \mathrm{EO}$ and $\mathrm{CDR}$. CH, PK, EO, CDR and AP designed the study methodology, AP co-ordinated organisation and participation. $\mathrm{CH}$ and AP conducted quantitative analysis, CH, PK, EO, CDR and AP conducted 
qualitative analysis. All authors contributed to writing and editing the final manuscript, and have approved the submission.

\section{Funding}

None declared.

\section{Availability of data and materials}

The datasets used and/or analysed during the current study are available from the corresponding author on reasonable request.

\section{Ethics approval and consent to participate}

Edinburgh Napier University School of Health and Social Care Research Integrity Committee gave approval for this study (Ref: SHSC20002). All participants gave written informed consent.

\section{Consent for publication}

Not applicable.

\section{Competing interests}

We declare no competing interests.

\section{Author details}

${ }^{1}$ School of Health and Social Care, Edinburgh Napier University, Sighthill Campus, Edinburgh EH11 4DN, UK. ²Department of Sport and Exercise Sciences, Durham University, Durham DH1 3HN, UK. ${ }^{3}$ Physical Activity for Health Research Centre, Institute for Sport, Physical Education and Health Sciences, University of Edinburgh, Edinburgh EH8 8AQ, UK.

Received: 6 August 2020 Accepted: 2 November 2020

Published online: 02 December 2020

\section{References}

1. Ding $\mathrm{D}$, Lawson KD, Kolbe-Alexander $T L$, et al. The economic burden of physical inactivity: a global analysis of major non-communicable diseases. Lancet. 2016;388(10051):1311-24 https://doi.org/10.1016/501406736(16)30383-X.

2. Guthold R, Stevens GA, Riley LM, et al. Worldwide trends in insufficient physical activity from 2001 to 2016: a pooled analysis of 358 populationbased surveys with 1.9 million participants. Lancet Glob Health. 2018;6(10): e1077-86 https://doi.org/10.1016/S2214-109X(18)30357-7.

3. Sowden S, Raine R. Running along parallel lines: how political reality impedes the evaluation of public health interventions. A case study of exercise referral schemes in England. J Epidemiol Community Health. 2008; 62(9):835-41 https://doi.org/10.1136/jech.2007.069781.

4. Fox K, Biddle S, Edmunds L, et al. Physical activity promotion through primary health Care in England. Br J Gen Pract. 1997;47:367-9.

5. National Institute for Health and Care Excellence, Exercise referral schemes to promote physical activity. 2014. Available at: https://www.nice.org.uk/ guidance/ph54/resources/physical-activity-exercise-referral-schemes-pdf-1 996418406085. [Accessed: 4 Jun 2020].

6. British Heart Foundation National Centre for Physical Activity and Health, A Tool Kit For the Design, Implementation \& Evaluation of Exercise Referral Schemes. 2010, Available at: http://www.ncsem-em.org.uk/wp-content/ uploads/2019/02/s2-current-practice.pdf. [Accessed: 4 Jun 2020].

7. Department of Health, Exercise referral systems: A national quality assurance framework. 2001, Available at: http://www.ncsem-em.org.uk/resources/ exercise-referral-toolkit/. [Accessed: 4 Jun 2020].

8. European Commission: An European Physical Activity on Prescription model [EUPAP] [847174]. Available at: https://webgate.ec.europa.eu/chafea_pdb/ health/projects/847174/summary. [Accessed: 18 Sept 2020].

9. Onerup A, Arvidsson D, Blomqvist Å, Daxberg E-L, Jivegård L, Jonsdottir $H$, Lundqvist S, Mellén A, Persson J, Sjögren P, et al. Physical activity on prescription in accordance with the Swedish model increases physical activity: a systematic review. Br J Sports Med. 2019;53(6):383-8.

10. American College of Sports Medicine: Exercise is Medicine, Health Care Providers Available at: https://www.exerciseismedicine.org/support_page. php/health-care-providers/ [Accessed: 18 Sept 2020].

11. Craike M, Britt H, Parker A, Harrison C. General practitioner referrals to exercise physiologists during routine practice: a prospective study. J Sci Med Sport. 2019;22(4):478-83.
12. Hanson $\mathrm{CL}$, Oliver EJ, Dodd-Reynolds $\mathrm{CJ}$, et al. We are failing to improve the evidence base for 'exercise referral': how a physical activity referral scheme taxonomy can help. Br J Sports Med. 2019. https://doi.org/10.1136/bjsports2019-101485.

13. Wade M, Mann S, Copeland RJ, et al. Effect of exercise referral schemes upon health and well-being: initial observational insights using individual patient data meta-analysis from the National Referral Database. J Epidemiol Community Health. 2020;74(1):32. https://doi.org/10.1136/jech-2019-212674.

14. Slade SC, Keating JL. Exercise prescription: a case for standardised reporting. Br J Sports Med. 2012;46(16):1110-3. https://doi.org/10.1136/bjsports-201109029014

15. Campbell F, Holmes M, Everson-Hock E, et al. A systematic review and economic evaluation of exercise referral schemes in primary care: a short report. Health Technol Assess. 2015;19(60):1-87. https://doi.org/10.3310/hta19600.

16. Pavey TG, Anokye N, Taylor A, et al. The clinical effectiveness and costeffectiveness of exercise referral schemes: a systematic review and economic evaluation. Health Technol Assess. 2011;15(44):1. https://doi.org/ 10.3310/hta15440

17. Oliver EJ, Hanson CL, Lindsey IA, et al. Exercise on referral: evidence and complexity at the nexus of public health and sport policy. Int I Sport Policy Politics. 2016:1-6. https://doi.org/10.1080/19406940.2016.1182048.

18. Hsu C-C, Sandford BA. The Delphi technique: making sense of consensus. Pract Assess Res Eval. 2007;12(10):1-8 https://doi.org/10.7275/pdz9-th90.

19. Dalkey N, Helmer O. An experimental application of the DELPHI method to the use of experts. Manag Sci. 1963;9(3):458-67 https://doi.org/10.1287/ mnsc.9.3.458.

20. Jünger S, Payne SA, Brine J, et al. Guidance on conducting and REporting DElphi studies (CREDES) in palliative care: recommendations based on a methodological systematic review. Palliat Med. 2017;31(8):684-706 https:// doi.org/10.1177/0269216317690685.

21. Okoli C, Pawlowski SD. The Delphi method as a research tool: an example, design considerations and applications. Inf Manag. 2004:42(1):15-29 https:// doi.org/10.1016/j.im.2003.11.002.

22. Diamond IR, Grant RC, Feldman BM, et al. Defining consensus: a systematic review recommends methodologic criteria for reporting of Delphi studies. J Clin Epidemiol. 2014;67(4):401-9 https://doi.org/10.1016/j.jclinepi.2013.12.002.

23. Centres for Disease Control and Prevention The Public Health System \& the 10 Essential Public Health Services. 2020, Available at: https://www.cdc.gov/ publichealthgateway/publichealthservices/essentialhealthservices.html. Accessed 4 June 2020

24. Duda JL, Williams GC, Ntoumanis N, et al. Effects of a standard provision versus an autonomy supportive exercise referral programme on physical activity, quality of life and well-being indicators: a cluster randomised controlled trial. Int J Behav Nutr Phys Act. 2011;11(1):1-15. https://doi.org/ 10.1186/1479-5868-11-10.

25. Moore GF, Raisanen L, Moore L, et al. Mixed-method process evaluation of the welsh National Exercise Referral Scheme. Health Educ. 2013;113(6):476501. https://doi.org/10.1108/HE-08-2012-0046.

26. Michie S, Richardson $M$, Johnston $M$, et al. The behavior change technique taxonomy (v1) of 93 hierarchically clustered techniques: building an international consensus for the reporting of behavior change interventions. Ann Behav Med. 2013;46(1):81-95. https://doi.org/10.1007/s12160-013-9486-6.

27. Gillison FB, Rouse P, Standage M, et al. A meta-analysis of techniques to promote motivation for health behaviour change from a self-determination theory perspective. Psychol Rev. 2019;3(1):110-30. https:/doi.org/10.1080/ 17437199.2018.1534071.

28. Hasson F, Keeney S, McKenna $\mathrm{H}$. Research guidelines for the Delphi survey technique. J Adv Nurs. 2000;32(4):1008-15. https://doi.org/10.1046/j.13652648.2000.t01-1-01567.x.

29. Brewer EW. Delphi Technique. In: Salkind NJ, editor. Encyclopedia of measurement and statistics. Thousand Oaks: Calif. SAGE; 2007. p. 241-6.

30. Keeney S, Hasson F, McKenna HP. A critical review of the Delphi technique as a research methodology for nursing. Int J Nurs Stud. 2001;38(2):195-200. https://doi.org/10.1016/S0020-7489(00)00044-4.

31. Nutbeam D, Bauman A. Evaluation in a nutshell : a practical guide to the evaluation of health promotion programs. North Ryde: McGraw-Hill; 2006. p. $1-126$.

\section{Publisher's Note}

Springer Nature remains neutral with regard to jurisdictional claims in published maps and institutional affiliations. 